\title{
Shear effects on bending behavior of CFRP floor panels
}

\author{
Y Gao, J Chen* and D Fox \\ School of Civil Engineering and Surveying \\ Faculty of Technology, University of Portsmouth, Portsmouth PO1 3AH, UK \\ *Corresponding address: iye.chen@port.ac.uk
}

Key words: Shear effect, Pultruded CFRP floor panel, Form factor, Shear deflection correction

\begin{abstract}
This article analytically and experimentally investigated the shear effects on the deflection of a carbon fibre reinforced polymer (CFRP) based building floor panel. The proposed CFRP floor panel was developed by same authors, which is a pultruded CFRP beam with an open crosssection and multi cells consisted of thin-walled plates. It aims to develop green buildings for saving energy and reducing $\mathrm{CO}_{2}$ emission in low carbon constructional industry. This article presents the investigation of shear effects on the deflection of the pultruded beam with an open cross-section and two cells consisted of thin-walled plates. Investigation includes analytical and experimental work. The formulations to calculate the shear effects on the deflection of the CFPR floor panel in two different loading cases were conducted analytically, and were validated by experimental work of scaled floor panels. Investigation found that the shear effect of proposed CFRP floor panel on the deflection is significant, and important when carrying out deflection check in designing the buildings with CFRP floor panels. A cross-sectional form factor regarding shear effects on the deflection and load-deflection correction factors were produced for further researches in the society of composite thin-walled structures and practical applications in the CFRP related constructional industry.
\end{abstract}


Y Gao, J Chen, etc.

\section{Introduction}

To speed up the development of low carbon constructional industry, a CFRP floor panel system was investigated by the same authors (Y Gao, J Chen, etc., 2013) [1]. In authors' previous work, the CFRP panel shown in Fig. 1 was designed to be made by carbon fibres and epoxy polymers, as a recommended standard building floor component, and was proposed to be pre-manufactured in factories by pultrusion. Authors' previous investigation was conducted using composites related design codes, etc. [3-22]. It can be seen from Fig. 1 that the CFRP panel is a pultruded beam with an open cross section and double cells consisted of number of thin-walled plates. Thin-walls have varied thickness with curved radius at the inner side. In order to verify the design, scaled CFRP floor panels were manufactured. Basic experimental investigation was reported in previous work [1]. As a part of outcomes from previous work, authors conducted four design curves for designing CFRP floor panels with different dimensions. One of design curves is regarding deflection against span, height and width of floor panels, and other three design curves are about maximum tensile stresses in transverse and through thickness directions, and maximum shear stress against varied dimensions in span, height and width, respectively. Previous work [1] indicated that deflection check plays an important role in designing such CFRP floor panels. This paper will focus on the investigation of shear effects on deflection. More detailed experimental work continued from previous work [1] will be analysed in conjunction with the analytical and numerical investigation in this paper to work out formulas to account the shear effects on deflection. There were four basic objectives in this investigation: 1) Theoretical analysis of shear effects; 2) Experimental work for verification; 3) Deflection of scaled test panel; 4) Analysis of full CFRP floor panel. To accomplish these objectives, a working program implementing two stages of investigation is presented in this paper. Firstly, theoretically conduct an equation for calculating deflection with shear effects, then experimental work of scaled floor panel will be applied to verify the theoretical work. Finally, conducted equations will be applied in the analysis of full CFRP floor panels. It should be noticed that the investigation in this paper was also supported by FEA modelling analysis.
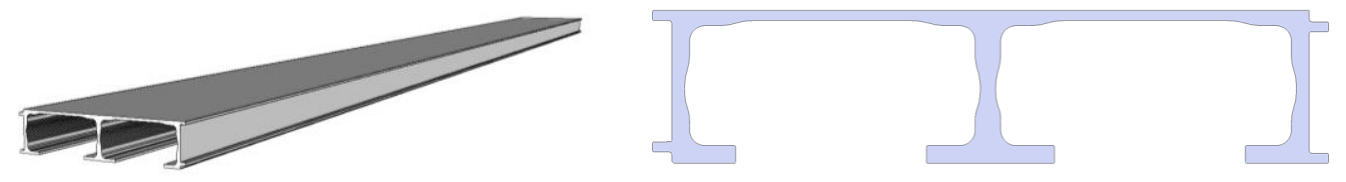
Figure 1: A CFRP panel and the cross-sectional view

\section{Theoretical analysis of shear effects}

\subsection{Deflection of a floor beam with an open cross-section due to bending}

In terms of bending-deflection theory [2], the deflection of beam with a symmetric open cross-section due to bending can be calculated by Equation 1 .

$$
\frac{d^{4} v}{d x^{4}}=-\frac{w}{E I}
$$

The deflection at the middle of the beam, with uniformly distributed load (UDL) and simple supports, can be calculated by Equation 2 .

$$
v_{\text {mid-span }}=-\frac{5 w L^{4}}{384 E I}
$$

The cross-section of the investigated CFRP floor panel is not exactly symmetric because of two side slits for over lapping shown in Figure 1[1]. Therefore, an exact equation to consider any effects due to this unsymmetrical feature on bending behavior is required.

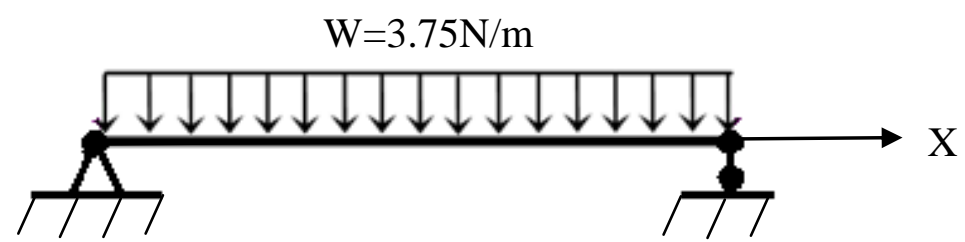

Figure 2: A beam with simple supports and uniformly distributed load

Figure 2 shows a beam with simple supports, subjected to an un-factored design load of $3.75 \mathrm{~N} / \mathrm{mm}$ given in previous work [1]. The bending moment at any point along the span (Xaxis) can be calculated by Equation 3 .

$$
M_{z}=\frac{w x(l-x)}{2}, M y=0
$$

In the case of a beam with symmetric cross-section, the bending moment and flexural rigidity can be presented by Equ. 4 . 
Y Gao, J Chen, etc.

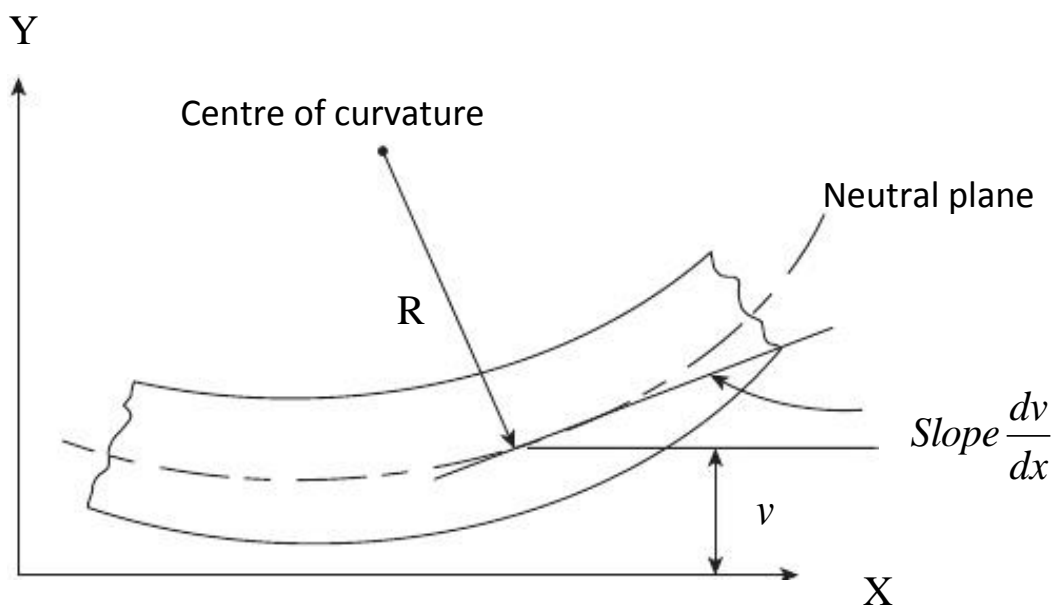

Figure 3: Deflection and curvature of a beam due to bending

$$
\frac{1}{R}=\frac{M}{E I}
$$

It can be seen from Figure 3 that the curved radius is perpendicular to the neutral axis. Now, consider a general beam with an unsymmetrical cross section shown in Figure 4. Assume that the deflection at some section of a beam is normal to the neutral axis. Thus, an absolute deflection $\zeta$ can be used to express the movement of the central $G$ to $G$ ' shown in Figure 4 . The components of $\zeta$, $\mathrm{u}$ and $\mathrm{v}$, are given by Equ. 5 as shown below.

$$
u=\zeta \sin \theta \quad v=\zeta \cos \theta
$$

The centre of curvature of the beam lies in a longitudinal plane perpendicular to the neutral axis of the beam and passes through the centric of any section.

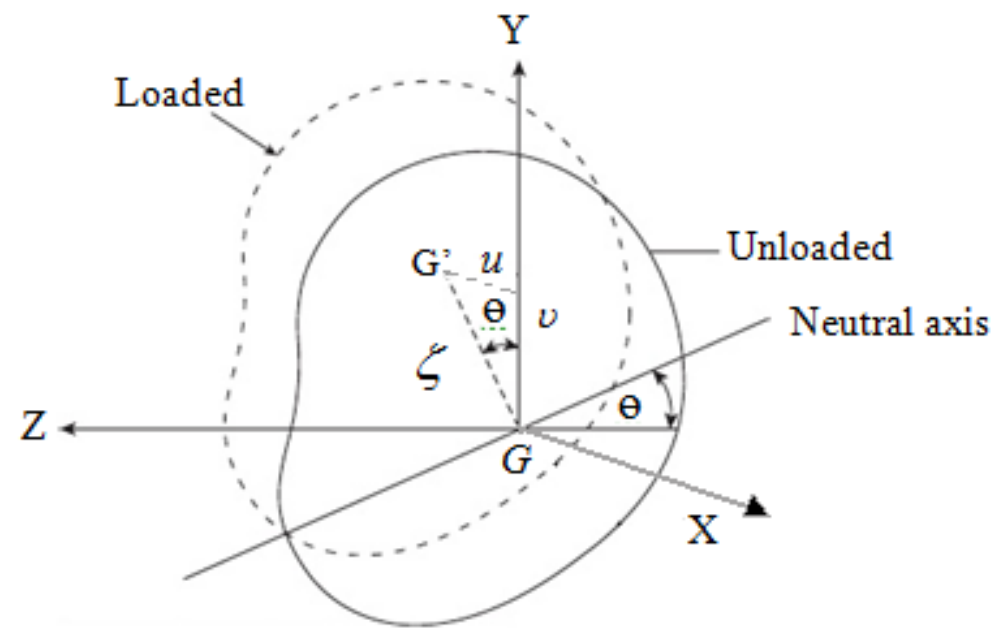

Figure 4: Deflection of a beam with an unsymmetrical cross-section 
Hence, for a radius of curvature $\mathrm{R}$, a relationship between $\mathrm{R}$ and deflection $\zeta$ can be obtained by a direct comparison with Equ. 4 given by Equ. 6 .

$$
\frac{1}{R}=\frac{d^{2} \zeta}{d_{x}^{2}}
$$

Substituting Equ. 5 into Equ. 6 results the Equ. 7.

$$
\frac{\sin \theta}{R}=\frac{d^{2} u}{d_{x}{ }^{2}} \quad \frac{\cos \theta}{R}=\frac{d^{2} v}{d_{x}{ }^{2}}
$$

Individual bending moment can be obtained by the integration of corresponding stress given in Equ. 8.

$$
M_{z}=-\int_{A} \sigma_{x} y d A, M_{y}=-\int_{A} \sigma_{x} z d A
$$

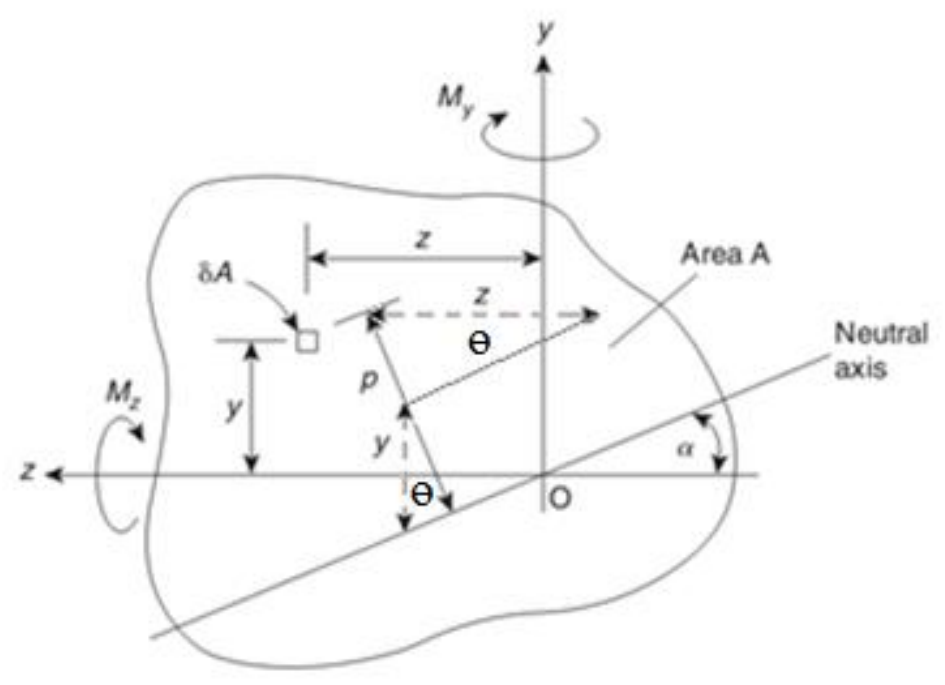

Figure 5: Bending of a beam with an unsymmetrical cross-section

The stress in Equ. 8 can be calculated by strain at any point with normal distance $\rho$ to neutral axis multiplying the young's modulus as shown in Equ. 9.

$$
\sigma_{x}=-\frac{E \rho}{R}(9)
$$

Referring to the Figure 5, Equ. 9 can be rewritten as 


$$
\sigma_{x}=-\frac{E}{R}(z \sin \theta+y \cos \theta)
$$

Substituting $\sigma_{x}$ from Eq. (10) into Eq. (8) obtains the following equation.

$$
\left.\begin{array}{l}
M z=\frac{E \sin \theta}{R} \int_{A} z y d A+\frac{E \cos \theta}{R} \int_{A} y^{2} d A \\
M y=\frac{E \sin \theta}{R} \int_{A} z^{2} d A+\frac{E \cos \theta}{R} \int_{A} z y d A
\end{array}\right\}
$$

In Equ. (11),

$$
\int_{A} z y d A=I_{z y} \quad \int_{A} y^{2} d A=I_{z} \quad \int_{A} z^{2} d A=I_{y}
$$

Equ. (11) may, therefore, be rewritten as

$$
\begin{aligned}
& \frac{E \sin \theta}{R}=\frac{M_{Y} I_{Z}-M_{Z} I_{Z Y}}{I_{Z} I_{Y}-I_{Z Y}^{2}} \\
& \frac{E \cos \theta}{R}=\frac{M_{Z} I_{Y}-M_{Y} I_{Z Y}}{I_{Z} I_{Y}-I_{Z Y}^{2}}
\end{aligned}
$$

Bring Equ. 7 into Equs. 12 and 13 results Equs. 14 and 15.

$$
\begin{aligned}
& \frac{d^{2} u}{d x^{2}}=\frac{M_{Y} I_{Z}-M_{Z} I_{Z Y}}{E\left(I_{Z} I_{Y}-I_{Z Y}^{2}\right)} \\
& \frac{d^{2} v}{d x^{2}}=\frac{M_{Z} I_{Y}-M_{Y} I_{Z Y}}{E\left(I_{Z} I_{Y}-I_{Z Y}^{2}\right)}
\end{aligned}
$$

Using Equ. 3, the Equ. 14 can be reduced to Equ.16.

$$
\frac{d u}{d x}=\frac{-w I_{Z Y}}{2 E\left(I_{Z} I_{Y}-I_{Z Y}^{2}\right)}\left(\frac{x^{2} l}{2}-\frac{x^{3}}{3}+C_{1}\right)
$$

Consider the symmetry in longitudinal, at the mid-span section $x=1 / 2$ the slope gradient $\mathrm{du} / \mathrm{dx}=0$. Hence:

$$
0=\frac{l^{3}}{8}-\frac{l^{3}}{24}+C_{1}
$$


Whence:

$$
C_{1}=-\frac{l^{3}}{12}
$$

Therefore:

$$
\frac{d u}{d x}=\frac{-w I_{Z Y}}{2 E\left(I_{Z} I_{Y}-I_{Z Y}^{2}\right)}\left(\frac{x^{2} l}{2}-\frac{x^{3}}{3}-\frac{l^{3}}{12}\right)
$$

Integrating Equ. 17 with respect to x results:

$$
u=\frac{-w I_{Z Y}}{2 E\left(I_{Z} I_{Y}-I_{Z Y}^{2}\right)}\left(\frac{x^{3} l}{6}-\frac{x^{4}}{12}-\frac{x l^{3}}{12}+C_{2}\right)
$$

When $\mathrm{x}=0, \mathrm{u}=0$, then $C_{2}=0$ can be achieved from the above equation, so we have:

$$
u=\frac{-w I_{Z Y}}{2 E\left(I_{Z} I_{Y}-I_{Z Y}^{2}\right)}\left(\frac{x^{3} l}{6}-\frac{x^{4}}{12}-\frac{x l^{3}}{12}\right)
$$

At the middle of the beam $x=1 / 2$,

$$
u=\frac{5 w l^{4} I_{Z Y}}{384 E\left(I_{Z} I_{Y}-I_{Z Y}^{2}\right)}
$$

By doing a similar work to conduct $\mathrm{u}$, the deflection $\mathrm{v}$ in vertical direction can be derived from Equ. (15) as below.

$$
v=\frac{w I_{Y}}{2 E\left(I_{Z} I_{Y}-I_{Z Y}^{2}\right)}\left(\frac{x^{3} l}{6}-\frac{x^{4}}{12}-\frac{x l^{3}}{12}\right)
$$

At the middle of the beam $x=1 / 2$,

$$
v_{l / 2}=\frac{-5 w l^{4} I_{Y}}{384 E\left(I_{Z} I_{Y}-I_{Z Y}^{2}\right)}
$$

Where, $w$ is distributed load, $I_{Z}$ and $I_{y}$ are the second moment of area about $\mathrm{Z}$ and $\mathrm{Y}$ axis, $I_{z y}$ is second moment of area about z-y plane, $l$ is the span of the beam. In Equ. 21, $I_{z y}$ presents the effect of an unsymmetrical cross-section on the deflection of beam. In the case of 
symmetrical cross-section, $I_{z y}=0$, thus Equ. 21 is the calculation of deflection at the middle of beam with symmetrical cross-section as same as Equ. 2 .

In order to find out the asymmetrical effect, the result from Equ. 21 will be used to compare the result from Equ. 2. Substituting the $w=3.75 \mathrm{~N} / \mathrm{mm}, \mathrm{A}=13026 \mathrm{~mm}^{2}, \mathrm{I}_{\mathrm{z}}=31786226 \mathrm{~mm}^{4}$, $I_{y}=391171840 \mathrm{~mm}^{4,} I_{z y}=653491 \mathrm{~mm}^{4}, L=6000 \mathrm{~mm}, E=130330 \mathrm{~Pa}$ and $\mathrm{G}=3590 \mathrm{~Pa}$ into Equ. 21 and Equ. 2 respectively conduct results as below:

Asymmetrical cross section:

$$
v_{l / 2}=-\frac{-5 \times 3.75 \times 6000^{4} \times 391171840}{384 \times 130330 \times\left(31786226 \times 391171840-653491^{2}\right)}=-15.2759 \mathrm{~mm}
$$

Symmetrical cross section:

$$
v_{l / 2}=\frac{-5 \times 3.75 \times 6000^{4}}{384 \times 31786226 \times 130330}=-15.2754 \mathrm{~mm}
$$

It can be seen from the above results that the effect of the asymmetrical cross section of the proposed floor CFRP panel on the deflection can be ignored. The formulas for calculating bending deflection of a beam with a symmetrical cross-section can be accepted in the application of the proposed CFRP floor panel to make the calculation simple.

\subsection{Shear effect on the deflection of a CFRP floor panel}

In general, the deflection of beam due to shear can be calculated from the follow equation [2].

$$
v_{s}=\frac{\beta}{G} \int_{L}\left(\frac{S_{y}}{A}\right) d x
$$

Where, $\mathrm{L}$ is span, $\mathrm{A}$ is the total area of cross-section, and $\mathrm{G}$ is material shear modulus, $\beta$ is defined as the form factor (Megson, 2005) and $S_{y}$ is shear force at the section investigated. It should be noted that eq. 6.22 is a general formula derived from the case of a beam with a solid cross-section [2]. Thus pplying eq. 6.22 in the case of a beam with an open crosssection and multi cells consisted of thin-walled plates results in an incorrect answer in comparison to a tested result. Therefore, it was suggested that the shear related deflection should be corrected considering the loading related distortion of such a cross-section using 
experimental work studied in this investigation. A similar work was reported by Schniepp (2002) [23] regarding the shear effect of a thin-walled CFRP beam used in bridges. Thus, the deflection at the middle of the investigated beam due to shear was proposed to be expressed by Equ. 6.23, under a UDL load:

$$
v_{s}=\frac{\beta \alpha w l^{2}}{8 A G}
$$

In this investigation, uniformly distributed load $\mathrm{w}=3.6 \mathrm{~N} / \mathrm{mm}, \mathrm{G}$ is material shear modulus 3590MPa given in the table 3, A was calculated as $3927 \mathrm{~mm}^{2}$ by AutoCad, span L is taken as $6000 \mathrm{~mm}$. The form factor $\beta$ in Equ. 23 will be theoretically derived to consider the shear effects on deflection in this particular case of the panel with an open cross-section and multi cells consisted of thin-walled plates, and validated by experimental work of a scaled test panel with a similar cross-section in the following section. It should be noticed that the $\alpha$ in Equ. 23 was suggested as a correction factor to account loading related distortional effects on the deflection of such panel with an open cross-section and multi cells. This deflection correction factor should vary with different loading cases. Point loading and uniformly distributed loading were considered in this investigation. The values of $\alpha$ were conducted as 4.28 and 1.8 in point load and uniformly distributed load case respectively in terms of experimental and analytical work given in following sections.

\subsection{Analysis of scaled test panels}

\subsubsection{Test samples}

The cross section of the designed test specimen can be seen in Fig. 6. The specimen consists of five elements, including a top plate and 4 channel section strips. The top plate was adhesively bonded on the top of four channel section strips. The middle web consists of two channel section strips bonded together back to back. This specimen was designed using a 1:20 ratio to the original design. The total width and height of the specimen are $25 \mathrm{~mm}$ and $7.5 \mathrm{~mm}$, respectively. That measurement means the specimen is equivalent to the original size of $500 \mathrm{~mm}$ width and $150 \mathrm{~mm}$ height. Because the hydraulic press oven has limited length $220 \mathrm{~mm}$ for samples, the test sample was designed with $200 \mathrm{~mm}$ span between two supports. The extra $20 \mathrm{~mm}$ was spate into $10 \mathrm{~mm}$ at each end of the sample for installation. Two 
different CFRP plates with thickness $0.5 \mathrm{~mm}$ and $0.4 \mathrm{~mm}$ for the top plate and the channel section, respectively. This scaled specimen is simplified from the designed model with the consideration of changing the complex shape of the cross section to one with a constant thickness.
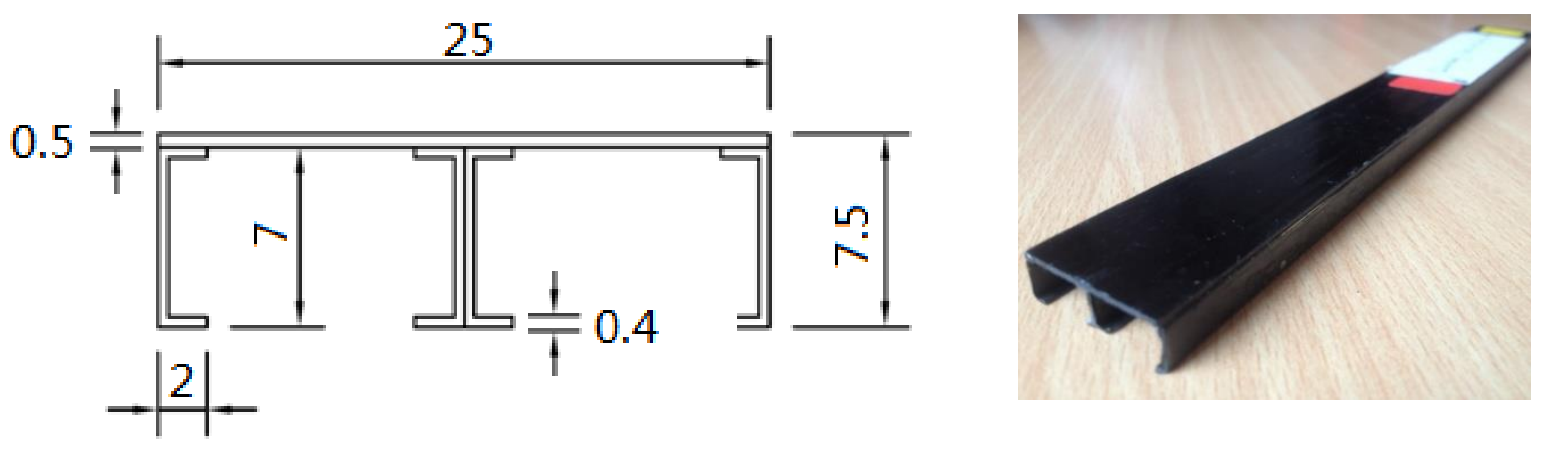

Figure 6: A cross-section view of scaled sample (unit for all dimensions: $\mathrm{mm}$ )

\subsubsection{Theoretical Analysis of scaled test panels}

As same as proposed full CFRP floor panel, the scaled test beam is an one-way spanning slab because fibres are placed along the way of the span of beam. It has similar cross-section shown in Figure 7 to the full CFRP floor panel. The dimension of cross-section of scaled test beam can be seen from Figure 8. Firstly, longitudinal bending stress can be simply calculated by Equ. 24 .

$$
\sigma_{x}=-\frac{M}{I z} y
$$

Where $\sigma_{x}$ is stress in fiber direction, $I z$ is second moment of area about $\mathrm{z}$ axis, $\mathrm{y}$ is the distance from neutral axis to the stress point. It can be seen from Equ. 24 that the maximum bending stress is located at the middle section of the slab because of the maximum bending moment applied at the middle section. Where, $M=2625 \mathrm{Nmm}, I z=201.36 \mathrm{~mm}^{4}, y=2.4 \mathrm{~mm}$. The bending stress distribution under design load is shown in Figure 7.

Shear stresses distribution at the cross-section shown in Figure 9 can be calculated by Equ. 25. 


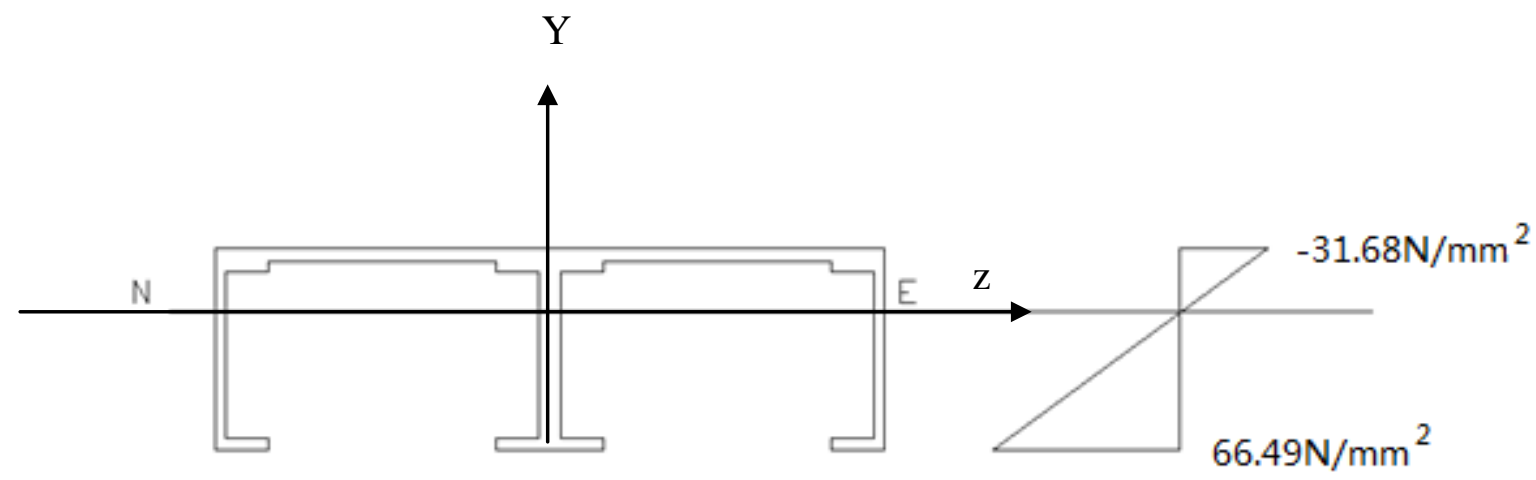

Figure 7: Bending stress distribution

$$
\tau=\frac{F A^{\prime} \bar{y}}{b_{0} I_{z}}
$$

Where, $\mathrm{F}$ is the maximum shear force, $\mathrm{A}^{\prime}$ is a variable area above $\bar{y}$, which is the distance of the centroid of the variable area from the neutral axis of the cross section, $b$ is variable width of the layer on which shear stress distribution is sought, and the value of $\mathrm{I}_{\mathrm{z}}$ was calculated as $201.36 \mathrm{~mm}^{4}$.

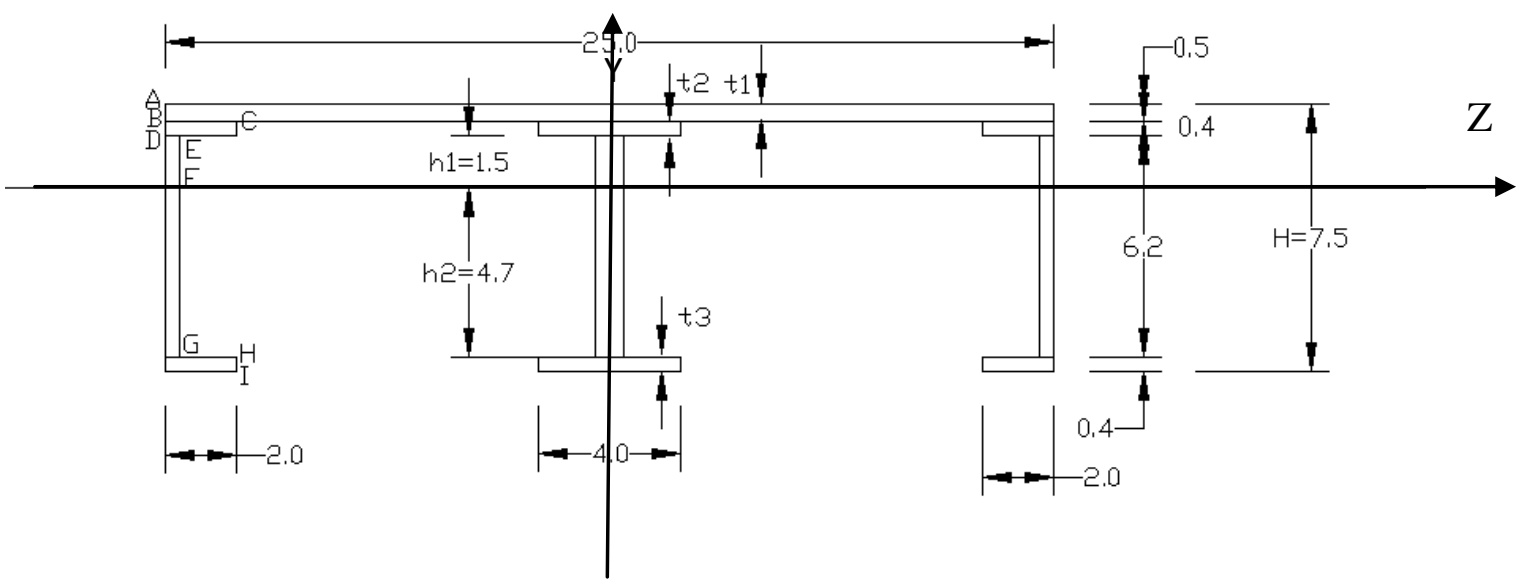


Y Gao, J Chen, etc.

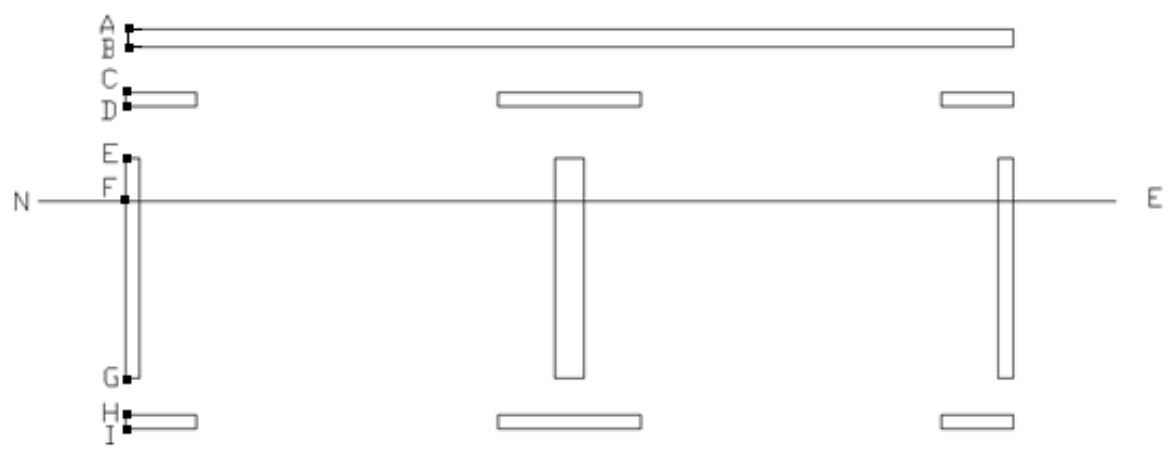

Figure 8: Dimension of specimen's cross-section

Shear stress at point A in Figure 8, $\tau_{A}=0$.

At point B,

$$
\mathrm{A}^{\prime}=\mathrm{Bt}_{1}, \mathrm{~b}=\mathrm{B}=25 \mathrm{~mm}, Z(y)=h_{1}+t_{2}+\frac{t_{1}}{2}=2.15
$$

Where, $\mathrm{Z}(\mathrm{y})$ is distance of the centroid of the variable area from top of the cross section

$$
\begin{gathered}
\bar{y}=2.4-Z(y)=0.25 \\
\tau_{B}=\frac{F B t_{1} \times\left(h_{1}+t_{2}+\frac{t_{1}}{2}\right)}{B I_{z}}=0.14 \mathrm{~N} / \mathrm{mm}^{2}
\end{gathered}
$$

At point $\mathrm{C}$,

$$
\begin{gathered}
\mathrm{A}^{\prime}=\mathrm{Bt}_{1}, \mathrm{~b}=8 \mathrm{~mm} \\
\bar{y}=h_{1}+t_{2}+\frac{t_{1}}{2}=2.15 \\
\tau_{C}=\frac{F B t_{1} \times\left(h_{1}+t_{2}+\frac{t_{1}}{2}\right)}{b I_{z}}=0.44 \mathrm{~N} / \mathrm{mm}^{2}
\end{gathered}
$$

At point $\mathrm{D}$,

$$
\mathrm{A}^{\prime}=\mathrm{Bt}_{1}+\mathrm{bt}_{2}, \mathrm{~b}=8 \mathrm{~mm}
$$


Y Gao, J Chen, etc.

$$
\begin{gathered}
\bar{y}=\frac{B t_{1} \times\left(h_{1}+t_{2}+t_{1} / 2\right)+t_{2} b \times\left(h_{1}+t_{2} / 2\right)}{A^{\prime}}=2.06 \mathrm{~mm} \\
\tau_{D}=\frac{F A^{\prime} \bar{y}}{b I_{z}}=0.5273 \mathrm{~N} / \mathrm{mm}^{2}
\end{gathered}
$$

At point $\mathrm{E}$,

$$
\begin{gathered}
\mathrm{A}^{\prime}=\mathrm{Bt}_{1}+8 \mathrm{t}_{2}, \mathrm{~b}=1.6 \mathrm{~mm} \\
\bar{y}=\frac{B t_{1} \times\left(h_{1}+t_{2}+t_{1} / 2\right)+t_{2} b \times\left(h_{1}+t_{2} / 2\right)}{A^{\prime}}=2.06 \mathrm{~mm} \\
\tau_{E}=\frac{F A^{\prime} \bar{y}}{b I_{z}}=2.6365 \mathrm{~N} / \mathrm{mm}^{2}
\end{gathered}
$$

At point $\mathrm{F}$,

$$
\begin{gathered}
\mathrm{A}^{\prime}=\mathrm{Bt}_{1}+\mathrm{t}_{2} \times 8+\mathrm{h}_{1} \times \mathrm{b}=18.1 \mathrm{~mm}^{2}, \mathrm{~b}=1.6 \mathrm{~mm} \\
\bar{y}=\frac{B t_{1} \times\left(h_{1}+t_{2}+t_{1} / 2\right)+t_{2} \times 8 \times\left(h_{1}+t_{2} / 2\right)+h_{1} b \times\left(h_{1} / 2\right)}{A^{\prime}}=1.88 \mathrm{~mm} \\
\tau_{F}=\frac{F A^{\prime} \bar{y}}{b I_{z}}=2.774 \mathrm{~N} / \mathrm{mm}^{2}
\end{gathered}
$$

At Point I, $\quad \tau_{I}=0$

At point $\mathrm{H}$,

$$
\begin{gathered}
\mathrm{A}^{\prime}=\mathrm{bt}_{3}=3.2 \mathrm{~mm}^{2}, \mathrm{~b}=8 \mathrm{~mm} \\
\bar{y}=h_{2}+\frac{t_{3}}{2}=4.9 \mathrm{~mm} \\
\tau_{h}=\frac{F A^{\prime} \bar{y}}{b I_{z}}=0.255 \mathrm{~N} / \mathrm{mm}^{2}
\end{gathered}
$$

At point $\mathrm{G}$,

$$
\mathrm{A}^{\prime}=8 \mathrm{xt}_{3}=3.2 \mathrm{~mm}^{2}, \mathrm{~b}=1.6 \mathrm{~mm}
$$


Y Gao, J Chen, etc.

$$
\begin{gathered}
\bar{y}=h_{2}+\frac{t_{3}}{2}=4.9 \mathrm{~mm} \\
\tau_{G}=\frac{F A^{\prime} \bar{y}}{b I_{z}}=1.276 \mathrm{~N} / \mathrm{mm}^{2}
\end{gathered}
$$

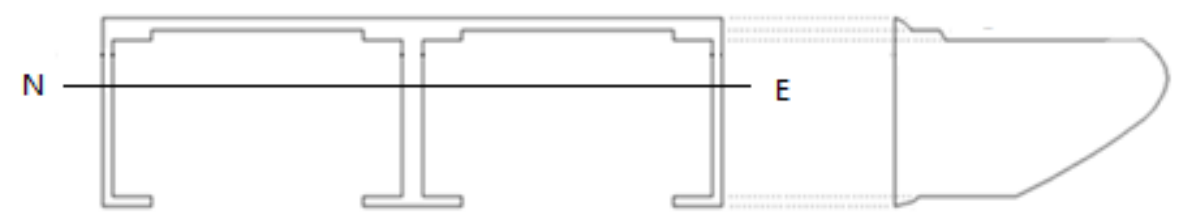

Figure 9: Shear Distribution

\subsection{Form factor}

The form factor $\beta$ can be calculated by Equ. 26 [2].

$$
\beta=\frac{A}{I_{z}{ }^{2}} \int_{y 1}^{y 2} \frac{\left(A^{\prime} \bar{y}\right)^{2}}{b} d y(26)
$$

Using Equ. 26, $\beta$ can be calculated by adding all contributions from each segment shown in Figure 8 as stated below.

Form factor $\beta_{A-B}$

$$
\begin{aligned}
& \beta_{A-B}=\frac{A}{I_{z}^{2}} \int_{1.9}^{2.4} \frac{\left(A^{\prime} \bar{y}\right)^{2}}{b} d y, \mathrm{~A}=28.82 \mathrm{~mm}^{2}, I=201 \mathrm{~mm}^{4} \\
& A^{\prime}=25 \times(2.4-y) \quad Z(y)=\frac{2.4-y}{2} \quad \bar{y}=2.4-Z(y) \\
& \beta_{A-B}=\frac{28.82}{201^{2} \times 25} \int_{1.9}^{2.4}\left(25 \times(2.4-y)\left(y+\frac{2.4-7}{2}\right)\right)^{2} d y=0.0036
\end{aligned}
$$

Form factor $\beta_{C-D}$

$$
\begin{aligned}
& \beta_{C-D}=\frac{A}{I_{z}^{2}} \int_{1.5}^{1.9} \frac{\left(A^{\prime} \bar{y}\right)^{2}}{b} d y \quad A^{\prime}=25 \times 0.5+8 \times(1.9-y) \\
& Z(y)=\frac{25 \times 0.5 \times 0.25+8 \times(1.9-y)(2.4-y) \div 2}{25 \times 0.5+8 \times(1.9-y)} \bar{y}=2.4-Z(y)
\end{aligned}
$$


$\beta_{C-D}=\frac{28.82}{201^{2} \times 6.8} \int_{1.5}^{1.9}\left(25+8(1.9-y)\left(24-\frac{25 \times 0.5 \times 0.25+8 \times(1.9-y)(2.4-y) \div 2}{25 \times 0.5+8 \times(1.9-y)}\right)\right)^{2} d y=0.031$

Form factor $\beta_{E-G}$

$$
\begin{aligned}
& \beta_{E-G}=\frac{A}{I_{z}^{2}} \int_{-4.7}^{1.5} \frac{\left(A^{\prime} \bar{y}\right)^{2}}{b} d y \quad A^{\prime}=25 \times 0.5+8 \times 0.4+(1.5-y) \times 1.6 \\
& Z(y)=\frac{25 \times 0.5 \times(0.5 \div 2)+8 \times 0.4 \times(0.5+0.4 \div 2)+1.6 \times\left(h_{1}-y\right)(0.9+0.5(1.5-y))}{25 \times 0.5+8 \times 0.4+(1.5-y) \times 1.6} \\
& \bar{y}=2.4-z(y) \\
& \beta_{E-G}=\frac{28.82}{201^{2} \times 1.6} \int_{-4.7}^{1.5}(25+8 \times 0.4+1.6(1.5-y)(24- \\
& \left.\left.\frac{25 \times 0.5 \times(0.5 \div 2)+8 \times 0.4 \times(0.5+0.4 \div 2)+1.6 \times\left(h_{1}-y\right)(0.9+0.5(1.5-y))}{25 \times 0.5+8 \times 0.4+(1.5-y) \times 1.6}\right)\right)^{2} d y=2.479
\end{aligned}
$$

Form factor $\beta_{H-I}$

$$
\begin{gathered}
\beta_{H-I}=\frac{A}{I_{z}^{2}} \int_{-5.1}^{-4.7} \frac{\left(A^{\prime} \bar{y}\right)^{2}}{b} d y \quad A^{\prime}=8 \times(5.1-y) \\
Z(y)=(5.1-y) / 2 \quad \bar{y}=5.1-Z(y) \\
\beta_{A-B}=\frac{28.82}{201^{2} \times 8} \int_{-5.1}^{-4.7}\left(8 \times(5.1-y)\left(y+\frac{5.1-7}{2}\right)\right)^{2} d y=0.0030
\end{gathered}
$$

Therefore, the form factor of this open-cross section of scaled test panel is summated as

$$
\beta=\beta_{A-B}+\beta_{C-D}+\beta_{E-G}+\beta_{H-I}=2.51
$$

\section{Experimental works}

There were 8 samples used in experimental tests [1]. Figure 10 shows load-deflection curves obtained from three point bending tests. It can be seen from Figure 10 that the failure loads ranged from $330 \mathrm{~N}$ to $490 \mathrm{~N}$ for most specimens except one marked \#3 specimen reached to $490 \mathrm{~N}$. Corresponding deflection to the failure loads ranged from $3.7 \mathrm{~mm}$ to $5.4 \mathrm{~mm}$. Load- 
deflection curves have significant drops at failure loads, due to large area debonded. The residual stiffness is very low after failure. It should be noted that load-deflection curves are not always smooth because of micro matrix cracks or fault from the adhesion. More details of test results can be referred to previous work [1].

Table 1 shows selected results, including maximum deflection and failure loads from six tested specimens. Table 2 presents statistical results, including the mean and standard deviation for the deflections and failure loads using stochastic theory. Averaged values for deflection and failure load are $4.7 \mathrm{~mm}$ and $407 \mathrm{~N}$ respectively. A corresponding mean curve was also plotted in Figure 10.

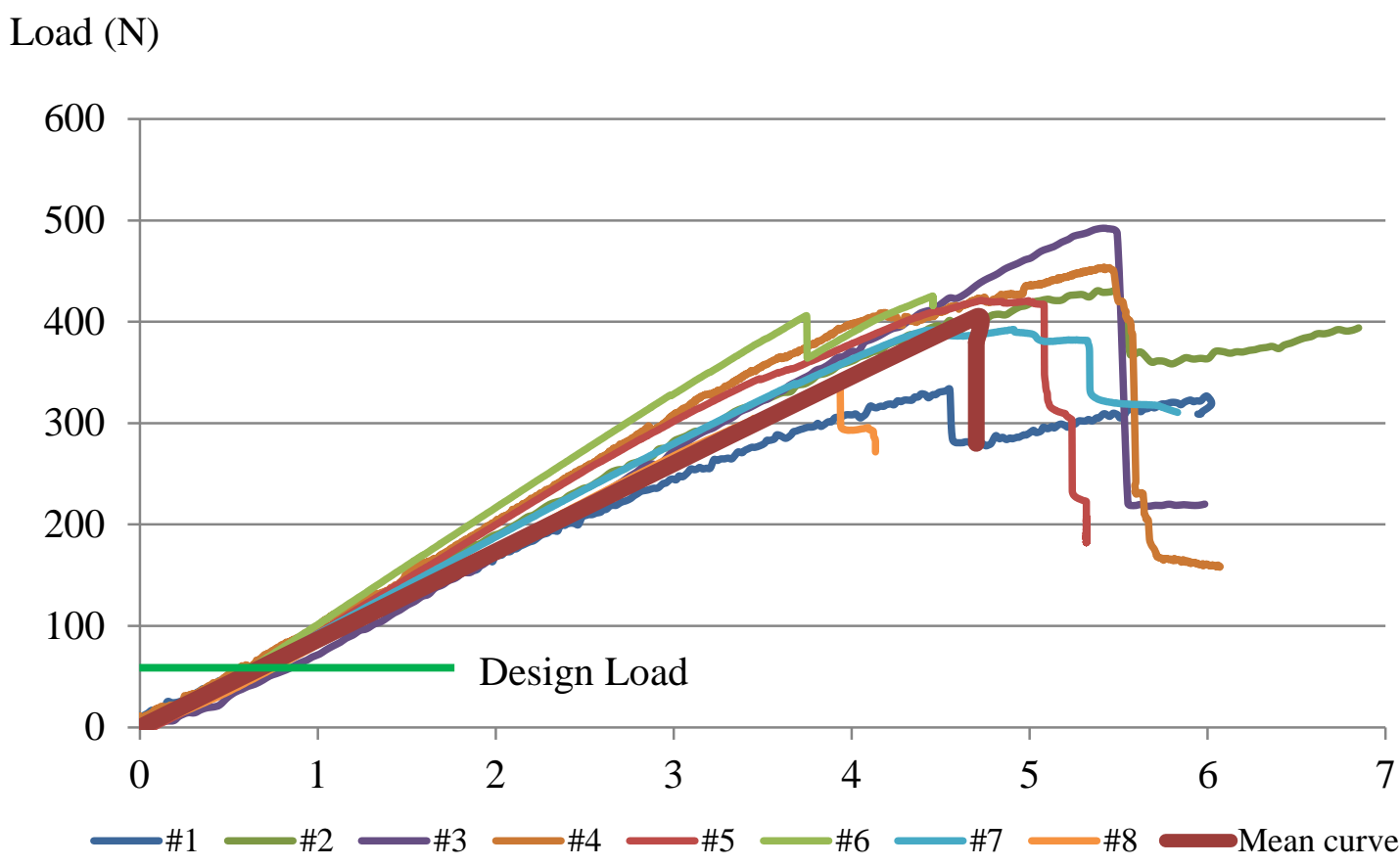

Deflection (mm)

Figure 10: Load-deflection curves

Table 2 presents statistical results, including the mean and standard deviation, for the deflection and failure load, according stochastic theory. According to the theory of the normal distribution, if the value of probability density is smaller than $4 \sigma$, the probability is less than $0.0001 \%$. In this investigation, the design value $\mathrm{F}_{\mathrm{d}}(53.5 \mathrm{~N})$ is smaller than the mean $\mu(407 \mathrm{~N})$ minus four times standard deviation $\sigma(54.7 \mathrm{~N})$ as shown in Equ. 27. 


$$
\mathrm{F}_{\mathrm{d}}<\mu-4 \sigma(27)
$$

Therefore, the failure probability against design value is $0 \%$. This statistical result proved that the loading capacity of the designed panel is high enough with $0 \%$ failure probability.

Table 1: Specimens' test results

\begin{tabular}{|c|c|c|c|c|c|c|c|c|c|}
\hline Specimen & $\# 1$ & $\# 2$ & $\# 3$ & $\# 4$ & $\# 5$ & $\# 6$ & $\# 7$ & $\# 8$ & Mean \\
\hline Failure Load (N) & 330 & 426 & 490 & 452 & 416 & 402 & 389 & 334 & 407 \\
\hline Deflection (mm) & 4.5 & 5.4 & 5.4 & 5.3 & 5.0 & 3.7 & 4.4 & 3.9 & 4.7 \\
\hline
\end{tabular}

Table 2: Statistical results

\begin{tabular}{|c|c|c|}
\hline Statistical Items & Mean & Standard Deviation $(\sigma)$ \\
\hline Failure Load (N) & 407 & 54.7 \\
\hline Design value & \multicolumn{2}{|c|}{ Failure Probability against design value } \\
\hline 53.50 & Mean - Design value $=350 \geqslant 4 \sigma=219,0 \%$ \\
\hline
\end{tabular}

\subsection{Conduction of load-deflection correction factor}

The test sample has a symmetric cross-section as shown in Fig. 6. Therefore, the bending deflection under a point load and a simple support can be calculated by the first item in Equ. 28. Meanwhile, the deflection due to shear cannot be ignored because this beam has an open cross-section and multi cells. The total deflection in the middle of the beam can be expressed by a combination of bending deflection and the deflection due to shear for the case with simple supports and a point load. The second item in Equ.28 is the calculation of shear deflection, which was actually conducted using Equ.22 for the case of a simply supported beam under a point load, and considering an open cross-section and multi cells. 


$$
v_{l / 2}=-\frac{P L^{3}}{48 E I_{z}}-\frac{\beta \alpha P L}{4 A G}
$$

In Equ.28, $\mathrm{I}_{\mathrm{Z}}=201.36 \mathrm{~mm}^{4}$ and $\mathrm{A}=28.82 \mathrm{~mm}^{2}$, calculated by AutoCad. The values for point load $\mathrm{P}$ and deflection were taken as means given in table 2. Material Young's modulus and shear modulus were taken as $130330 \mathrm{MPa}$ and $3590 \mathrm{MPa}$ from table 3 . In order to conduct the deflection correction factor in the point loading case, tested mean deflection $4.7 \mathrm{~mm}$, failure load $404 \mathrm{~N}$ and the form factor ( $\beta=2.51$ ) were used in Equ. 28. Thus the shear deflection corrector $\alpha$ was worked out as 4.28 for the point loading case. This conducted load-deflection correction factor is a physically determined correction factor because conduction used tested data in Equ.28. From Equ.28, the deflection $\mathrm{V}_{1 / 2}(4.7 \mathrm{~mm})$ includes a bending deflection of $2.6 \mathrm{~mm}$, so the value of shear deflection is $2.1 \mathrm{~mm}$, which is about $45 \%$ of total deflection at the middle of beam. This indicates that the shear effect on deflection is significant because of an open cross-section with multi cells consisted of thin-walled plates. It should be noticed that previous research by Schniepp (2002) used the item of PL/(kAG) as shear stiffness to replace the second item in Equ.28. In Schniepp's investigation, the parameter $\mathrm{k}$ was determined by experimental work and varied with different loading cases. Actually, $\mathrm{k}$ is equivalent to the item of $4 /(\beta \alpha)$ in this investigation.

Using a similar approach presented above, load deflection correction factors in the case of a beam under a UDL load and simple supports can be worked out. Unfortunately, because of the equipment restraints in the laboratory, the required tests of the scaled samples under UDL and simple supports were not completed by the lab work during this investigation. As a complement, it was suggested the load-deflection correction factor could be worked out using the UDL related deflection calculation shown in Equ. 29. The required values for deflection and loading can be obtained from FEA modelling.

$$
v_{1 / 2 L}=-\frac{5 w L^{4}}{384 E I_{Z}}-\frac{\beta \alpha w L^{2}}{8 A G}
$$


Table 3: Material Properties

\begin{tabular}{lcc}
\hline \multicolumn{1}{c}{ CFRP(WE91 HSC 100) } & & \\
Elastic modulus & E11 & $130.33 \mathrm{GPa}$ \\
& E22 & $7.22 \mathrm{GPa}$ \\
Shear modulus & E33 & $7.22 \mathrm{GPa}$ \\
& G12 & $4.23 \mathrm{GPa}$ \\
Poisson ratio (XY) & G23 & $4.23 \mathrm{GPa}$ \\
Poisson ratio (XZ) & $v 12$ & 0.34 \\
Poisson ratio (YZ) & $v 13$ & 0.34 \\
Mass Density & $v 23$ & 0.02 \\
Longitudinal Tensile Strength & $\rho$ & $1502 \mathrm{~kg} / \mathrm{m}^{3}$ \\
Longitudinal Compressive Strength & $\mathrm{Ux}(\mathrm{t})$ & $1433.6 \mathrm{MPa}$ \\
Transverse Tensile Strength & $\mathrm{Ux}(\mathrm{c})$ & $984.2 \mathrm{MPa}$ \\
Transverse Compressive Strength & $\mathrm{Uy}(\mathrm{t})$ & $32.5 \mathrm{MPa}$ \\
Through Thickness Tensile Strength & $\mathrm{Uy}(\mathrm{c})$ & $108.3 \mathrm{MPa}$ \\
Through Thickness Compressive Strength & $\mathrm{Uy}(\mathrm{t})$ & $32.5 \mathrm{MPa}$ \\
In-plan shear strength & $108.3 \mathrm{MPa}$ \\
\hline
\end{tabular}

In Equ.29, the form factor $\beta$ is taken as the same value 2.51 and all other material and beam section properties were kept as the same values as that in the point loading case. In a corresponding FEA modelling analysis, a UDL of $-0.188 \mathrm{~N} / \mathrm{mm}$ was used, predicted deflection was $-0.19 \mathrm{~mm}$. Thus, bringing $-0.19 \mathrm{~mm}$ together with all other parameters into Equ.29 results in $\alpha=1.8$ in the case of the beam under UDL and simple supports. Table 4 shows all conducted load-deflection correction factors together with the form factor. Thus, these conducted factors based on a scaled panel will be used in the detailed calculation of deflection of a full CFRP panel in the following section.

It should be noted that in table 4 the theoretical deflections are exactly the same with a tested mean or a modelling prediction because they were used in the conduction of correction factors. However, FEA modelling prediction of the deflection of a full CFRP panel using these deflection correction factors conducted from a scaled panel will be a validation given in 
the following section. It can be seen from table 4 that the theoretical shear deflection is about $45 \%$ and $21 \%$ of total deflection in the point load and UDL cases, respectively. This demonstrates the shear effect of a scaled panel with an open cross-section is significant.

Table 4 Form factor and load-deflection correction factors conducted from a scaled panel

\begin{tabular}{|c|c|c|c|c|c|}
\hline \multirow{3}{*}{$\begin{array}{l}\text { Loading } \\
\text { case }\end{array}$} & \multicolumn{5}{|c|}{$\begin{array}{l}\text { Scaled sample under un-factored design load and simple supports } \\
\text { load (point load } 37.5 \mathrm{~N} \text {, UDL } 0.188 \mathrm{~N} / \mathrm{mm} \text { ), form factor } \beta=2.51\end{array}$} \\
\hline & \multirow{2}{*}{$\begin{array}{l}\text { Load-deflection } \\
\text { correction factor } \\
\alpha \alpha\end{array}$} & \multirow[b]{2}{*}{ Deflection mean $(\mathrm{mm})$} & \multicolumn{3}{|c|}{$\begin{array}{l}\text { Theoretical } \\
(\mathrm{mm})\end{array}$} \\
\hline & & & $\begin{array}{l}\text { Bending } \\
\text { def. }\end{array}$ & $\begin{array}{c}\text { Shear } \\
\text { def. }\end{array}$ & Total \\
\hline $\begin{array}{l}\text { Point } \\
\text { load }\end{array}$ & 4.28 & -0.433 (test) & -0.238 & -0.195 & -0.433 \\
\hline UDL & 1.8 & -0.19 (FEA) & -0.149 & -0.041 & -0.19 \\
\hline
\end{tabular}

\subsection{Theoretical calculation of deflections of full CFRP panels}

Theoretical calculation of the deflections of full CFRP panels under un-factored design load and simple supports was carried out using the proposed formulas given in last section. Investigation includes FEA modelling work only for validation. The proposed formulas in the last section can be used for calculating the maximum deflection at the middle of a simple supported full CFRP panel with thin-walled and open cross-section. Two different loading cases were considered. Equ. 26 is for the point load case and Equ.29 is for the UDL case. In these equations, the form factor $\beta$ is taken as 2.5 , the load-deflection correction factor $\alpha$ is taken as 4.3 for the point load case and 1.8 for the UDL case in accordance with the work given in the last section.

In the point load case, $\mathrm{P}=0.0075 \times 500 \times 6000=22500 \mathrm{~N}, \mathrm{~A}=13026 \mathrm{~mm}^{2}, \mathrm{I}_{\mathrm{z}}=31786226 \mathrm{~mm}^{4}$, $\mathrm{L}=6000 \mathrm{~mm}, \mathrm{E}=130330 \mathrm{~Pa}, \mathrm{G}=3590 \mathrm{~Pa}, \beta=2.5$ and $\alpha=4.3$. Bringing these parameters into Equ. 6.28, the deflection of a full panel with a pointed load and simple supports can be calculated as: 
Y Gao, J Chen, etc.

$-\frac{22500 \times 6000^{3}}{48 \times 31786226 \times 130330}-\frac{2.5 \times 4.3 \times 22500 \times 6000}{4 \times 13026 \times 3590}=-24.441-7.217=-32.23 \mathrm{~mm}$

The theoretically calculated deflection $-32.23 \mathrm{~mm}$ agrees with the FEA modelling prediction 30.78 shown in table 5 . The difference is only $5 \%$. The theoretical shear deflection $-7.217 \mathrm{~mm}$ is about $22 \%$ of total deflection in this case.

In the UDL case, $w=0.0075 \times 500=3.75 \mathrm{~N} / \mathrm{mm}, \mathrm{A}=13026 \mathrm{~mm}^{2}, \mathrm{I}_{\mathrm{z}}=31786226 \mathrm{~mm}^{4}, \mathrm{~L}=6000 \mathrm{~mm}$, $\mathrm{E}=130330 \mathrm{~Pa}, \mathrm{G}=3590 \mathrm{~Pa}, \beta=2.5$ and $\alpha=1.8$. Bringing these parameters into Equ.29, the deflection of a full panel under UDL can be expressed as:

$$
-\frac{5 \times 3.75 \times 6000^{4}}{384 \times 31786226 \times 130330}-\frac{2.5 \times 1.8 \times 3.75 \times 6000^{2}}{8 \times 13026 \times 3590}=-15.275-1.624=-16.906 \mathrm{~mm}
$$

This theoretically calculated deflection of $-16.9 \mathrm{~mm}$ basically agrees with the FEA modelling prediction of $-17.9 \mathrm{~mm}$ shown in table 5 . The difference between theory and modelling is about $6 \%$. The shear deflection $-1.624 \mathrm{~mm}$ in this UDL case is $10 \%$ of total deflection.

It can be seen from table 5 that the theoretical deflection agrees well with the FEA modelling prediction in both the point load and UDL cases. Therefore, the conducted form factor 2.5 and load-deflection correction factor, 4.3 (pointed load) and 1.8 (UDL), are basically suitable for the calculation of deflection of the full CFRP panel. It also can be seen from tables 4 and 5 that the shear effect on the deflection of a full panel is reduced by about $50 \%$ compared to that in the scaled panel.

\subsection{Conclusion and future work}

The shear effects on the deflection of a scaled and a full CFRP panel was identified by experimental work and FEA modelling analysis respectively in this investigation. This certainly proved that the form factor and load-deflection correction factors conducted from scaled panel are basically suitable in the calculation of the deflection of a full CFRP panel. Therefore, Equ.28 and 29 are the final formulas for calculating the deflection of a simply supported CFRP full panel under a point load or a UDL, in which the form factor $\beta$ should be taken as 2.5, the deflection correction factors $\alpha$ should be be taken as 4.3 and 1.8 in the point load and UDL cases respectively to correct the shear effects on deflection. The shear effects 
on the deflection of a full panel were represented by $22 \%$ and $10 \%$ of total deflection in the point load and UDL cases respectively. Obviously, this shear effect cannot be ignored, and the shear effect on deflection reduces as the span of the panel increases because the increased span of the panel will increase the bending effect. Future work would analytically and experimentally investigate the shear effects of the CFRP floor panel under a fixed condition.

Table 5: Deflections of a full CFRP panel given by theory and FEA modeling

\begin{tabular}{|c|c|c|c|c|c|}
\hline \multirow{3}{*}{$\begin{array}{l}\text { Loading } \\
\text { case }\end{array}$} & \multicolumn{5}{|c|}{$\begin{array}{l}\text { Full panel under un-factored design load and simple supports } \\
\text { load (point load } 22500 \mathrm{~N} \text {, UDL } 3.75 \mathrm{~N} / \mathrm{mm} \text { ), form factor } \beta=2.51\end{array}$} \\
\hline & \multirow{2}{*}{$\begin{array}{l}\text { Load-deflection } \\
\text { correction factor } \alpha\end{array}$} & \multirow{2}{*}{$\begin{array}{l}\text { FEA modelling } \\
\text { deflection }(\mathrm{mm})\end{array}$} & \multicolumn{3}{|c|}{$\begin{array}{c}\text { Theoretical } \\
(\mathrm{mm})\end{array}$} \\
\hline & & & $\begin{array}{c}\text { Bending } \\
\text { def. }\end{array}$ & $\begin{array}{c}\text { Shear } \\
\text { def. }\end{array}$ & Total \\
\hline Point load & 4.28 & -30.78 & -24.44 & -7.79 & -32.43 \\
\hline UDL & 1.8 & -17.94 & -15.28 & -1.62 & -16.91 \\
\hline
\end{tabular}

\section{REFERENCES}

1. Y Gao, J Chen, Z Zhang and D Fox, An advanced FRP floor panel system in buildings, Composites Structures, 96, 683-690, 2013.

2. Megson, T.H.G., Structural and Stress Analysis, Second Edition, Elsevier, London, 2005.

3. Bakis CE, Bank LC, Brown VL, et al., Fiber-reinforced polymer composites for construction-state-of-the-art review, J. Compos. 2002; 6(2), 73-87.

4. Keller T, Haas $\mathrm{C}$ and Vallee $\mathrm{T}$, Structural concept, Design, and Experimental Verification of a Glass Fiber-Reinforced Polymer Sandwich Roof Structure. J. of Compos. For Construction 2008; 12(4), 454-468.

5. Keller T, Material-Tailored use of FRP Composite in Bridge and Building Construction, Invited lecture, CIAS International Seminar, Cyprus, 2007. <http://www.4emme.it/CIPRO\%20ATTI\%20PER\%20INTERNET/Prof.\%20Keller.pdf>.

6. Vallee T, Adhesively bonded lap joints of pultruded GFRP shapes, doctoral thesis No. 2964, Swiss Federal Institute of Technology EPFL, Switzerland, 2004.

7. Duthinh D, Connections of Fiber-Reinforced Polymer (FRP) Structural Members: A Review of the State of the Art, National Institute of Standards and Technology, 2000.

8. Brooker O, Concrete buildings schemes design manual, Surrey, cement and concrete industry publication, 2009.

9. Clarke JL, Structural design of polymer composites: EUROCOMP design code and handbook, London, E \& FN Spon, 1996. 
10. Kim HY, Lee YH and Lee SY, Ultimate strength of a GFRP deck panel for temporary structures, Compos Struct 2011; 93(2):528-537.

11. ASCE, Structural Plastics Design Manual, ASCE Manuals and Reports on Engineering Prastics; 63, A. S. o. c. Egineering, 1984.

12. Gurit, Guide to Composite. P27, 2012. $<$ http://www.gurit.com/files/documents/guide-to-compositesv4pdf.pdf $>$.

13. Hutchinson JA and Singleton M J, STARTLINK COMPOSITE HOUSING , 3rd International Conference on Advanced Composites in Construction; University of Bath, UK, 2007.

14. Keoleian GA, Kendall A, Chandler R, Helfand GE, Lepech M and Li VC, Life-Cycle Cost Model for Evaluating the Sustainability of Bridge Decks, Proceedings of the International Workshop on Life-Cycle Cost Analysis and Design of Civil Infrastructure Systems; Cocoa Beach, Florida, p143-150, 2005.

15. Wilkinson M, Thermal Properties of Building Materials. <http://people.bath.ac.uk/absmaw/BEnv1/properties.pdf > [rerieved 23.04.2011].

16. LUSAS user manual; http://www.lusas.com, 2011.

17. Ready Homes Enterprises, A report of FRP domes house, USA, 2002.

18. Campilho RDSG, etc., Tensile behaviour of three-dimensional carbon-epoxy adhesively bonded single- and double-strap repairs, Int. J. Adhes 2009; 29, 678-686.

19. Chen J, A numerical investigation of thermal related matrix shrinkage cracking and delamination in composite T-piece specimens using a modified interface cohesive model, Thermoplastic Composite Materials 2012; Vol. 25, No. 3, p267-282.

20. Hashin Z. Failure criteria for unidirectional fibre composites, ASME Journal of Applied Mechanics 1980, Vol. 47 (2), pp 329-334.

21. KNAUFDRYWALL. Soffit Lining Systems. 〈http://whowithwhat.com/images/product_downloads/iiMFSuspendedCeilings.pdf > [retrieved 13.04.2011].

22. Patel, J. K., \& Read, C. B., Handbook of the normal distribution, Vol. 150. CRC Press, 1996.

23. Schniepp, T. J., Design Manual Development for a Hybrid, FRP Double-Web Beam and Characterization of Shear Stiffness in FRP Composite Beams, Master thesis, etd08152002-212736, Virginia Polytechnic and State University, 2002. 